\title{
Rendimento industrial, eficiência de fabricação e características físico-químicas de queijo colonial produzido de leite com dois níveis de células somáticas
}

\author{
[Industrial yield, manufacturing efficiency and physical and chemical characteristics of colonial cheese \\ produced from milk with two levels of somatic cells] \\ C.A. Mattiello ${ }^{1}$, S.M. Silveira ${ }^{2}$, F. Carli ${ }^{3}$, A. Cunha Júnior ${ }^{4}$, D.R.M. Alessio ${ }^{1}$, A. Pelizza ${ }^{1}$, \\ L.L Cardozo ${ }^{1}$, A. Thaler Neto ${ }^{1}$ \\ ${ }^{1}$ Universidade do Estado de Santa Catarina - Lages, SC \\ ${ }^{2}$ Instituto Federal Catarinense - Concórdia, SC \\ ${ }^{3}$ Ministério da Agricultura, Pecuária e Abastecimento - Concórdia, SC \\ ${ }^{4}$ Embrapa Suínos e Aves - CNSPA - Concórdia, SC
}

\begin{abstract}
RESUMO
Com base em dois níveis de contagem de células somáticas (CCS) do leite utilizado como matéria-prima, determinou-se influência no rendimento e na eficiência de fabricação do queijo colonial, em escala industrial. Os dois níveis de CCS foram formados do leite captado pela indústria, baixa CCS $(<500.000$ células $/ \mathrm{mL}$ ) e alta CCS ( $\geq 500.000$ células $/ \mathrm{mL}$ ), sendo produzidos sete lotes de queijo para cada nível. O rendimento foi avaliado com rendimento simples (litros de leite $/ \mathrm{kg}$ de queijo produzido) e rendimento seco (litros de leite/kg de sólidos totais de queijo produzido). A eficiência de fabricação do queijo foi avaliada por meio das perdas de sólidos no soro de queijo. Mediante análises multivariadas, demonstrouse a relação entre altas CCS e a diminuição no rendimento simples e seco de queijo colonial, que apresentou também menor eficiência de fabricação, sem alterar a composição do queijo. Além disso, determinaram-se dados relativos às características físico-químicas de queijo colonial, o qual ainda não possui um regulamento técnico de identidade e qualidade. Conclui-se que a qualidade do leite tem influência direta na produção dos queijos e que, ao utilizar matéria-prima com alta CCS, a indústria assume os prejuízos do menor rendimento e da menor eficiência de fabricação dos queijos coloniais.
\end{abstract}

Palavras-chave: qualidade do leite, células somáticas, rendimento industrial, queijo colonial

\begin{abstract}
From two somatic cells count levels (SCC) of the milk used as raw material, the influence on the yield and cheese-making efficiency of colonial cheese was determined on an industrial scale. Both SCC levels were formed from milk received by the industry, being low SCC ( $<500.000$ cells $/ \mathrm{mL})$ and high SCC $(\geq 500.000$ cells $/ \mathrm{mL})$, and seven batches of cheese were produced for each level. The yield was evaluated as simple yield (liters of milk/kg of cheese produced) and dry yield (liters of milk/kg of total solids of cheese produced). The cheese-making efficiency was evaluated by the loss of solids in cheese whey. Multivariate analysis showed a relationship between high SCC and decrease in simple and dry colonial cheese yield, which also had lower manufacturing efficiency, without altering the composition of the cheese. Moreover, data on the physical and chemical characteristics of colonial cheese were determined, that does not have Technical Regulation of Identity and Quality. We conclude that the quality of milk has a direct influence on the production of cheeses and, when using raw materials with high SCC, the industry takes the costs of worsening in performance and manufacturing efficiency in colonial cheese.
\end{abstract}

Keywords: milk quality, somatic cells, industrial yield, colonial cheese

Recebido em 21 de março de 2017

Aceito em 13 de novembro de 2017

E-mail: cecilia@veterinaria.med.br 


\section{INTRODUÇÃO}

O queijo colonial, típico do sul do Brasil, era produzido antigamente de forma artesanal e com o uso de leite cru pelos imigrantes europeus que habitavam essa região. Atualmente é produzido em laticínios de pequeno e médio porte, utilizando-se leite pasteurizado. Segundo o Sistema de Informação Gerencial de Inspeção Federal, do Ministério da Agricultura, Pecuária e Abastecimento (Mapa), entre 2010 e 2014, Paraná, Santa Catarina e Rio Grande do Sul, juntos, produziram, sob inspeção federal, mais de 7,1 mil toneladas de queijo colonial. Apesar da grande importância desse queijo para a região, ainda não foi estabelecido um Regulamento de Identidade e Qualidade (RTIQ) pelo Ministério da Agricultura, Pecuária e Abastecimento (Mapa).

A Instrução Normativa $n^{\circ} 62$ (Brasil, 2011) é a normatização que rege os critérios mínimos de qualidade do leite no Brasil e estabelece o limite máximo de contagem de células somáticas (CCS) de 500 mil cél./mL de leite, tendo sido prorrogados os limites até 2018 para o sul do Brasil pela Instrução Normativa $n^{\circ} 7$ de 2016 (Brasil, 2016).

As células somáticas do leite são formadas por células de descamação epitelial natural da glândula mamária e por células de defesa do organismo, que migram do sangue para a glândula mamária, na tentativa de combater os agentes causadores da mastite. A CCS no leite é uma metodologia apreciada internacionalmente como critério de avaliação da sanidade da glândula mamária (Akers e Nickerson, 2011). A redução da CCS, indicador indireto da qualidade do leite, é uma das grandes prioridades do setor, pois a alta CCS está sempre relacionada negativamente com a qualidade do leite cru, uma vez que diminui a atividade secretora da glândula mamária, afetando o volume e a composição do leite produzido (Boland et al., 2013).

A principal alteração na composição do leite causada pela alta de CCS é a diminuição do teor de caseína, lactose e dos minerais cálcio e fósforo, que pode impedir o adequado processamento industrial. Além disso, a mastite é um risco para a higiene do leite, por possivelmente conter microrganismos patogênicos devido à inflamação.
O alto nível de células somáticas na matériaprima utilizada para fabricação de queijos é um tema continuamente estudado, em razão da sua importância econômica sobre o rendimento e a qualidade dos queijos. Demonstraram-se, em condições laboratoriais, as mais diversas alterações que podem ocorrer em decorrência da alta CCS, como: aumento do tempo de coagulação do leite (Klei et al., 1998), diminuição da firmeza do coágulo formado (Le Roux et al., 2003), maior perda de componentes do leite para o soro (Politis e Ng-Kwai-Hang, 1988), menor rendimento (Matioli et al., 2000; Le Roux et al., 2003; Coelho et al., 2014) e alterações de características organolépticas e de textura (Chen et al., 2010).

A literatura sobre as alterações em queijos produzidos com matéria-prima de alta CCS em condições reais de produção industrial é escassa. Em estudos dessa natureza, um grande número de variáveis afeta a eficiência do processo. Por meio de análises estatísticas multivariadas é possível o estudo dessas variáveis de maneira conjunta.

Diante do exposto, o objetivo do experimento foi avaliar o efeito de dois níveis de células somáticas sobre o rendimento industrial e a eficiência de fabricação de queijo colonial em escala industrial, além de levantar dados sobre a composição físico-química desse queijo para auxiliar na elaboração de um RTIQ pelo Mapa.

\section{MATERIAL E MÉTODOS}

O estudo foi conduzido durante os meses de abril e maio de 2015, em uma indústria de laticínios, sob vigilância do Serviço de Inspeção Federal (SIF), localizada na microrregião de Concórdia, oeste de Santa Catarina.

Foram formados dois grupos de seis produtores de leite cada, os quais forneciam leite ao laticínio parceiro, com base nos níveis de células somáticas, dividindo-os em grupo de alta CCS e baixa CCS, visando à produção de lotes de queijos oriundos de leite de cada grupo. Esses grupos foram definidos por meio do acompanhamento da CCS das propriedades participantes nos três meses prévios ao início do estudo, sendo o limiar utilizado para definir os grupos de 500 mil células $/ \mathrm{mL}$, de acordo com a legislação IN n 62/2011 (Brasil, 2011), vigente 
no país no momento do estudo. Para cada um dos dois níveis de CCS, foram produzidos sete lotes de queijo colonial na indústria, em um delineamento inteiramente ao acaso, com dois tratamentos e sete repetições.

O leite de cada grupo foi armazenado separadamente, desde os compartimentos do caminhão isotérmico que fazia a captação e o transporte do leite das propriedades para a indústria, respeitando-se a norma estabelecida pela Instrução Normativa $n^{\circ}$ 62/2011 (Brasil, 2011) de armazenamento por, no máximo, $48 \mathrm{~h}$ na propriedade rural. $\mathrm{Na}$ recepção desse caminhão na indústria, uma amostra do leite cru era coletada diretamente de cada compartimento, após homogeneização. O leite era encaminhado para a pasteurização rápida $\left(72\right.$ a $75^{\circ} \mathrm{C}$ durante 15 a 20 segundos) em pasteurizador a placas com capacidade para $6 \mathrm{mil} \mathrm{L/h}$, seguida pela padronização da gordura em $3 \%$. O leite de cada grupo (alta ou baixa CCS) era pasteurizado isoladamente, não havendo mistura com o restante do leite da indústria e, após a pasteurização, seguia diretamente para o tanque de produção do queijo colonial.

Os queijos foram produzidos em tanque retangular, de inox, camisa dupla, com capacidade para 2000L. Foram utilizados, em média, 1350L de leite por lote, sendo o queijo fabricado de forma padronizada em todos os lotes, com adição de fermento láctico (BV DEX $\left.06^{\circledR}\right)$ - pré-maturação por $30 \mathrm{~min}$, adição de cloreto de cálcio, corante natural de urucum (Urucum BV R25 ${ }^{\circledR}$ ) e coalho (Coalho líquido $\left.\mathrm{BV}^{\circledR}\right)$. Ao atingir o ponto do coágulo, aproximadamente 40min após a adição do coalho, foi realizado o corte manual por liras (horizontais e verticais). Prosseguia-se com a enformagem, a prensagem e a salmoura (12 horas em tanques exclusivos para lotes de queijo colonial), a secagem em câmara fria por quatro dias $\left(6^{\circ} \mathrm{C}\right)$, a embalagem à vácuo (polietileno) e a maturação $\left(10\right.$ dias a $\left.6^{\circ} \mathrm{C}\right)$, totalizando 15 dias até o final da produção, momento em que dois queijos de cada lote foram coletados, pois estavam prontos para comercialização.

O rendimento do queijo foi calculado de duas maneiras: a) rendimento simples, volume de leite necessário para a elaboração de um quilograma de queijo $(\mathrm{L} / \mathrm{kg})$, dividindo-se o volume de leite utilizado pela soma da massa dos queijos obtidos; b) rendimento seco, volume de leite por quilograma de matéria seca (L/kg MS). O rendimento simples da fabricação do queijo $(\mathrm{L} / \mathrm{kg})$ foi calculado no quinto dia após a fabricação, no momento da embalagem, após a secagem (quatro dias a $6^{\circ} \mathrm{C}$ ), e o rendimento seco no $15^{\circ}$ dia.

Para cada lote de queijo produzido, uma amostra de leite cru foi coletada em frasco contendo conservante Bronopol ${ }^{\circledR}$ e enviada ao Centro de Pesquisa e Diagnóstico em Alimentos (Cidasc/UnC), credenciado à Rede Brasileira de Laboratórios de Controle de Qualidade do Leite (RBQL) para a análise de composição centesimal por equipamento automatizado por infravermelho (Bentley Combisystem, Bentley Instruments ${ }^{\circledR}$, Inc., USA), conforme as recomendações de International Dairy Federation (IDF) $141 \mathrm{C}$ e contagem de células somáticas por citometria de fluxo (Delta Combiscope, Advanced Instruments ${ }^{\circledR}$, Inc., USA) seguindo o protocolo para leite cru ISO 133662/International Dairy Federation (IDF) 148-2.

Uma segunda amostra de leite cru, coletada em frasco estéril e sem adição de conservante, mas mantida sob refrigeração até o momento do processamento, foi enviada para o Laboratório de Microbiologia de Alimentos do Instituto Federal Catarinense - IFC/Câmpus Concórdia, para as análises de enumeração de mesófilos aeróbios (Brasil, 2003) e psicrotróficos (Compendium..., 2001).

Uma amostra de soro de queijo foi coletada ao final da produção de cada lote, no tanque, para se avaliar a composição centesimal por equipamento automatizado por infravermelho no laboratório do Centro Estadual de Pesquisa e Diagnóstico em Alimentos (Cidasc/UnC). As perdas de componentes sólidos do leite cru para o soro de queijo foram utilizadas como indicadores de eficiência de fabricação dos queijos.

Para a realização das análises de composição centesimal dos queijos, amostras de queijo no $15^{\circ}$ dia de fabricação foram congeladas e enviadas para o Laboratório de Análises FísicoQuímicas (LAFQ) da Embrapa Suínos e Aves, localizado em Concórdia/SC. Previamente aos ensaios físico-químicos, foi realizada a liofilização das amostras, em um liofilizador LJI- 
030 ${ }^{\circledR}$ (JJ Científica, São Carlos, SP, Brasil). Os ensaios basearam-se nas metodologias para análises físico-químicas de alimentos do Instituto Adolfo Lutz (Métodos..., 2008) e Brasil (1996).

Os dados obtidos foram analisados por meio de técnica de análises multivariadas (análise fatorial), utilizando-se o pacote estatístico $\mathrm{SAS}^{\circledR}$, sendo os dados previamente padronizados pelo procedimento STANDARD e a análise fatorial realizada mediante o uso do procedimento FACTOR, com rotação Promax. Os níveis de CCS foram codados com 0 (CCS < 500.000) e 1 $(\mathrm{CCS}>500.000)$. Com base nos autovalores, foram mantidos dois ou três fatores em cada análise, sendo os resultados apresentados nas respectivas dimensões, de modo que os resultados representam as relações positivas ou contrárias entre as variáveis utilizadas nas análises, e as comunalidades demonstram a relevância de cada variável.

\section{RESULTADOS}

O valor médio de CCS para o grupo de baixa CCS foi de 373 mil células/mL, e para o grupo de alta foi de 652 mil células/mL (Tab. 1). Em média, foram necessários $8,72 \mathrm{~L}$ de leite para produzir $1 \mathrm{~kg}$ de queijo ou $16,13 \mathrm{~L}$ para produzir um kg de matéria seca de queijo.

Tabela 1. Médias \pm desvio-padrão da composição, contagem de células somáticas (CCS), enumeração de microrganismos mesófilos e psicrotróficos do leite cru, de acordo com os grupos de CCS

\begin{tabular}{ccc} 
Grupo & CCS $<500.000$ & CCS $>500.000$ \\
\hline Variável leite cru & Média \pm DP & Média \pm DP \\
CCS x $10^{3}$ & $372 \pm 85$ & $652 \pm 99$ \\
Composição $(\mathrm{g} / 100 \mathrm{~g})$ & & \\
Gordura (\%) & $3,96 \pm 0,74$ & $4,18 \pm 0,45$ \\
Proteína (\%) & $3,36 \pm 0,07$ & $3,33 \pm 0,03$ \\
Lactose (\%) & $4,21 \pm 0,04$ & $4,19 \pm 0,04$ \\
Sólidos totais & $12,53 \pm 0,85$ & $12,62 \pm 0,67$ \\
Sólidos desengordurados & $8,57 \pm 0,13$ & $8,54 \pm 0,11$ \\
Qualidade microbiológica & & \\
Mesófilos (log10 UFC/mL) & $6,83 \pm 0,70$ & $6,84 \pm 0,46$ \\
Psicrotróficos (log10 UFC/mL) & $6,88 \pm 0,38$ & $7,21 \pm 0,56$ \\
\hline
\end{tabular}

Os valores médios para os principais componentes do leite cru (Tab. 1) encontram-se em conformidade com os parâmetros estabelecidos pela IN $n^{\circ} 62$ (Brasil, 2011) para leite cru refrigerado. Os teores de lactose não possuem limites estabelecidos pela normativa IN $n^{\circ} 62 / 2011$. Segue-se, portanto, o Regulamento de Inspeção Industrial e Sanitária de Produtos de Origem Animal - Riispoa Brasil (1952), que determina teores mínimos de $4,3 \%$ de lactose. Dessa forma, os valores médios encontrados para lactose (Tab. 1) estão abaixo do limite mínimo.

Em uma análise fatorial, em que foram relacionados os dois níveis de CCS e a composição do leite cru com o rendimento simples de queijo (L de leite/kg de queijo produzido), demonstrou-se que existe relação entre a CCS, o rendimento e os componentes sólidos do leite (Tab. 2). A soma dos dois primeiros fatores explicou $73,14 \%$ da variância total. No fator 1, observa-se a relação positiva entre os teores de gordura, proteína e lactose do leite cru e a relação contrária desses componentes com o rendimento e a CCS, isto é, a elevada concentração de sólidos determina a necessidade de menor quantidade de leite para produzir um $\mathrm{kg}$ de queijo. Nesse mesmo fator, observa-se uma relação positiva entre a CCS do leite cru e o rendimento do queijo, sendo necessária maior quantidade de leite com alta CCS para confeccionar um $\mathrm{kg}$ de queijo. O rendimento simples para o leite de baixa CCS foi de 8,49 litros de leite/kg de queijo, contra 8,94 para o leite de alta CCS, o que representa uma redução de aproximadamente $5,3 \%$ no rendimento. $\mathrm{O}$ fator 2 mostra uma relação positiva entre CCS e teor de gordura do leite cru. Resultados similares foram observados para a relação da composição do leite e da CCS com o rendimento seco do queijo (Tab. 2). 
Tabela 2. Cargas fatoriais, comunalidades e percentual de variância das variáveis utilizadas na análise fatorial que relaciona contagem de células somáticas e composição do leite cru e rendimento simples e seco de queijo

\begin{tabular}{cccc}
\hline Variáveis & \multicolumn{2}{c}{ Fatores } & \multirow{2}{*}{ Comunalidade } \\
\cline { 2 - 3 } & \multicolumn{2}{c}{ Fator 1 } & Fator 2 \\
\hline Proteína & Rendimento simples & 0,8477 \\
Lactose & 0,8832 & 0,3463 & 0,6989 \\
Rendimento simples & 0,8248 & $-0,0538$ & 0,5222 \\
Gordura & $-0,7219$ & 0,0395 & 0,8488 \\
CCS & 0,4442 & 0,8472 & 0,7397 \\
\%Variância & $-0,4646$ & 0,6741 & \\
\hline & 48,13 & 25,01 & 0,8426 \\
Proteína & Rendimento seco & 0,7335 \\
Lactose & 0,9155 & 0,0784 & 0,3317 \\
Rendimento seco & 0,8008 & $-0,2928$ & 0,8374 \\
Gordura & $-0,5759$ & 0,0010 & 0,7414 \\
CCS & 0,5768 & 0,7180 & \\
\%Variância & $-0,3151$ & 0,7970 & 24,85 \\
\hline
\end{tabular}

A influência dos grupos de CCS sobre o rendimento simples de queijo também foi avaliada, relacionando-as com a composição do soro (Tab. 3), e a soma dos fatores representou $67,29 \%$ da variação total. De acordo com o fator 1 , o rendimento simples de queijo $(\mathrm{L} / \mathrm{kg})$, o teor de lactose do soro e a CCS do leite cru relacionam-se positivamente entre si e apresentam relação contrária com o teor de gordura do soro. No fator 2, pode-se observar a relação positiva entre a CCS do leite cru, a caseína e a proteína do soro. As relações com a composição do soro foram similares quando foi analisado o efeito do rendimento seco do queijo.

A estatística descritiva das características físicoquímicas dos queijos coloniais, agrupados de acordo com a CCS, segue na Tab. 4.

Tabela 3. Cargas fatoriais, comunalidades e percentual de variância das variáveis utilizadas na análise fatorial que relaciona contagem de células somáticas do leite cru, composição do soro de queijo e rendimento simples e seco de queijo

\begin{tabular}{|c|c|c|c|}
\hline \multirow[t]{2}{*}{ Variáveis } & \multicolumn{2}{|c|}{ Fatores } & \multirow[t]{2}{*}{ Comunalidade } \\
\hline & Fator 1 & Fator 2 & \\
\hline \multicolumn{4}{|c|}{ Rendimento simples } \\
\hline Rendimento simples & 0,8382 & $-0,1623$ & 0,7127 \\
\hline Lactose soro & 0,6489 & $-0,0767$ & 0,4219 \\
\hline Gordura soro & $-0,9019$ & 0,1097 & 0,8153 \\
\hline Caseína soro & $-0,2811$ & 0,8339 & 0,7436 \\
\hline Proteína soro & $-0,1866$ & 0,7717 & 0,6123 \\
\hline CCS & 0,4800 & 0,6703 & 0,7317 \\
\hline \%Variância & 38,88 & 28,41 & \\
\hline \multicolumn{4}{|c|}{ Rendimento seco } \\
\hline Rendimento seco & 0,8258 & $-0,2323$ & 0,7055 \\
\hline Lactose soro & 0,6964 & $-0,0497$ & 0,4853 \\
\hline Gordura soro & $-0,8989$ & 0,0756 & 0,8081 \\
\hline Caseína soro & $-0,3155$ & 0,8292 & 0,7434 \\
\hline CCS & $-0,1600$ & 0,6962 & 0,7062 \\
\hline Proteína soro & 0,4387 & 0,7520 & 0,5817 \\
\hline \%Variância & 30,12 & 28,05 & \\
\hline
\end{tabular}


Tabela 4. Médias \pm desvio-padrão da composição e das características físico-químicas dos queijos coloniais, agrupados de acordo com a contagem de células somáticas

\begin{tabular}{ccc} 
Grupo & CCS $<500.000$ & CCS $>500.000$ \\
Variável Queijo & Média \pm DP & Média \pm DP \\
\hline Umidade $(\%)$ & $46,8 \pm 1,5$ & $45,1 \pm 1,1$ \\
Extrato etéreo $(\%)$ & $24,5 \pm 1,7$ & $25,4 \pm 1,5$ \\
Proteína bruta $(\%)$ & $21,7 \pm 2,4$ & $22,6 \pm 1,3$ \\
Sódio $(\mathrm{mg} / \mathrm{kg})$ & $6357 \pm 962$ & $6266 \pm 1185$ \\
Potássio $(\mathrm{mg} / \mathrm{kg})$ & $646 \pm 49$ & $648 \pm 69$ \\
Cálcio $(\mathrm{mg} / \mathrm{kg})$ & $7180 \pm 560$ & $6908 \pm 604$ \\
Fósforo $(\mathrm{mg} / \mathrm{kg})$ & $4029 \pm 309$ & $3910 \pm 388$ \\
Energia bruta $(\mathrm{kcal} / \mathrm{kg})$ & $3578 \pm 111$ & $3691 \pm 116$ \\
\hline
\end{tabular}

$\mathrm{Na}$ análise fatorial da relação grupos de CCS com a composição e as características físicoquímicas do queijo colonial (Tab. 5), foram avaliados três fatores, e a soma dos fatores representou $95,13 \%$ da variação total. De acordo com os fatores 1,2 e 3 , a CCS não apresentou relação com a umidade, os teores de gordura, a proteína e os minerais, assim como com a energia bruta do queijo colonial.

Tabela 5. Cargas fatoriais, comunalidades e percentual de variância das variáveis utilizadas na análise fatorial que relaciona contagem de células somáticas do leite cru e composição físico-química de queijo

\begin{tabular}{ccccc}
\hline Variáveis & \multicolumn{3}{c}{ Fatores } & \multirow{2}{*}{ Comunalidade } \\
\cline { 2 - 4 } & \multicolumn{3}{c}{ Composição do queijo } & Fator 3 \\
\hline Proteína & 0,9816 & $-0,18286$ & 0,2401 & 0,9820 \\
Sódio & 0,9787 & $-0,1872$ & 0,2436 & 0,9836 \\
Cálcio & $-0,8667$ & 0,4540 & -00525 & 0,9322 \\
Potássio & $-0,9256$ & 0,4376 & 01096 & 0,9232 \\
Energia bruta & $-0,1177$ & 0,9628 & 04136 & 0,9420 \\
Fósforo & $-0,2770$ & 0,9372 & 04672 & 0,9429 \\
Gordura & $-0,4347$ & 0,8596 & 0,2532 & 0,9317 \\
Umidade & $-0,6738$ & $-0,7099$ & -05377 & 0,9342 \\
CCS & 0,0237 & 0,5102 & 0,9937 & 0,9892 \\
\%Variância & 57,30 & 31,67 & 0,06 & \\
\hline
\end{tabular}

\section{DISCUSSÃO}

Pior rendimento simples a partir de leite com maior CCS também foi encontrado em trabalhos realizados com outros tipos de queijos. Klei et al. (1998) encontraram uma diminuição de 4,34\% no rendimento do queijo cottage quando em CCS

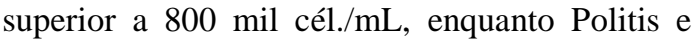
Ng-Kwai-Hang (1988) observaram que, ao se aumentar a CCS de $100 \mathrm{mil}$ cél. $/ \mathrm{mL}$ para $900 \mathrm{mil}$ cél. $/ \mathrm{mL}$, ocorreu um decréscimo de $11 \%$ no rendimento do queijo cheddar. No Brasil, a redução de rendimento em queijos minas frescal foi relatada, na ordem de $9,81 \%$, quando eles foram produzidos com leite de CCS $\geq 600 \mathrm{mil}$ cél./mL comparado a CCS < 200 mil cél./mL (Matioli et al., 2000) e, para queijo muçarela, houve redução de $18,3 \%$ quando os queijos eram elaborados com leite, ao se compararem grupos $\leq$ $200 \mathrm{mil} \mathrm{cél./mL} \mathrm{e}>750 \mathrm{mil}$ cél./mL (Coelho et al., 2014). Deve-se considerar que os trabalhos referentes ao rendimento dos queijos citados acima foram realizados em laboratório, com situações ideais de controle, diferentemente do presente trabalho, que foi realizado em condições reais de produção em uma indústria de laticínios, onde inúmeras variáveis não podem ser totalmente controladas.

Existe uma dependência entre o rendimento de queijo, a composição do leite e a incorporação dos componentes sólidos do leite pela coagulação, especialmente dos teores de proteína e gordura (Furtado, 2005). A diminuição no rendimento dos queijos pode estar relacionada à diminuição nas concentrações de caseína, nas 
alterações no balanço eletrolítico e no aumento da atividade de enzimas oriundas das células somáticas no leite cru (Auldist e Hubble, 1998). A alteração na concentração de caseína ocorre devido à redução na síntese na glândula mamária e ao aumento da atividade proteolítica das enzimas sobre esse sólido durante a mastite (Mazal et al., 2007). Nessas condições de inflamação, o epitélio da glândula mamária não faz adequadamente as trocas com a corrente sanguínea, por isso ocorre o desequilíbrio eletrolítico, em especial aumento na concentração dos minerais sódio e cloro e redução de cálcio e fósforo (Schallibaum, 2001).

A relação positiva entre os teores de gordura, proteína e lactose do leite cru e a relação contrária desses componentes com o rendimento e a CCS (fator 1, Tab. 2) indicam que elevada CCS está relacionada ao menor teor de sólidos no leite cru e à diminuição no rendimento, isto é, será necessário maior volume de leite para produzir $1,0 \mathrm{~kg}$ de queijo. Vianna et al. (2008) e Alessio et al. (2016) também relataram redução nos teores de lactose no leite quando em alta CCS.

No fator 2 (Tab. 2), observa-se a relação positiva entre a CCS e o teor de gordura. $\mathrm{O}$ aumento do teor de gordura no leite quando em mastite não está completamente elucidado, mas, em um estudo que avaliou o aumento da CCS do leite de 450 mil para 849 mil células $/ \mathrm{mL}$, Ma et al. (2000) também encontraram um aumento no teor de gordura de $3,43 \%$ para $4,04 \%$. Os autores atribuíram esse aumento no teor de gordura do leite ao decréscimo no volume de leite produzido, que foi de $30 \%$, em resposta ao processo inflamatório. A discrepância nas relações entre CCS e teor de gordura nos dois fatores (Tab. 2) pode estar relacionada à grande variabilidade que ocorreu nos teores de gordura, tanto no leite com alta quanto baixa CCS, o que fica evidenciado pelo elevado desvio-padrão (Tab. 1).

As perdas dos componentes sólidos para o soro são utilizadas para se avaliar a eficiência da fabricação do queijo. A relação positiva entre a CCS do leite cru e os teores de lactose (fator 1, Tab. 3) e caseína e proteína do soro (fator 2, Tab. 3 ) indica que quanto maior a CCS no leite cru, maiores serão as perdas de sólidos no soro de queijo e menor será, portanto, a eficiência de fabricação do queijo. Politis e Ng-Kwai-Hang (1988), ao avaliarem a eficiência da produção do queijo cheddar, encontraram médias de perdas para o soro de queijo de $28,63 \%$ e de $6,78 \%$ para proteína e caseína, respectivamente, comparando leite com alta e baixa CCS.

A perda da gordura do leite para o soro é dependente de diversos fatores, tais como teor de proteína, tempo e temperatura de pasteurização, $\mathrm{pH}$, acidez e temperatura do leite no momento em que o coalho é adicionado (Furtado, 2005). Tendo em vista todas essas variáveis, é possível que a relação contrária encontrada no fator 1 (Tab. 3) entre rendimento do queijo e CCS do leite cru e a gordura no soro possa sofrer influência de variáveis externas, pois na literatura encontra-se que, em situações de leite de alta CCS, as perdas de gordura para o soro aumentaram (Matioli et al., 2000) ou não sofreram influência (Mazal et al., 2007), contradizendo o encontrado neste trabalho.

A legislação brasileira para leite cru refrigerado, IN n 62 (Brasil, 2011), limita a contagem de microrganismos mesófilos em até $300.000 \mathrm{UFC} / \mathrm{mL}$, equivalente a $5,48 \log _{10}$ UFC/mL. Como é possível observar na Tab. 1, as contagens verificadas durante as análises do leite cru para a produção dos queijos coloniais apresentaram-se muito além do limite estabelecido. Silva et al. (2010) avaliaram o silo de estocagem de dois laticínios e também encontraram contagens altas de mesófilos aeróbios, $8,15 \log _{10} \quad \mathrm{UFC} / \mathrm{mL}$ e $8,45 \log _{10}$ $\mathrm{UFC} / \mathrm{mL}$, e atribuíram a elevada carga microbiana do leite às condições de estocagem e higiene dos tanques nas propriedades e no transporte do leite até o silo do laticínio.

A enumeração de microrganismos psicrotróficos não está englobada pela IN $n^{\circ}$ 62/2011, mas sabe-se que é imprudente a fabricação de produtos oriundos de leite cru com contagem de psicrotróficos superior a $6,7 \log _{10} \mathrm{UFC} / \mathrm{mL}$ (Pinto et al., 2006). Os resultados encontrados (Tab. 1) foram superiores ao limite descrito na literatura e semelhantes aos encontrados por Silva et al. (2010), que enumeraram os microrganismos psicrotróficos em silos de leite industriais. As fontes mais comuns de contaminação dos produtos lácteos por bactérias psicrotróficas são utilização de água contaminada e práticas de higiene impróprias (Murphy e Boor, 2000). Os 
maiores problemas que esses microrganismos podem causar nos queijos são sabores indesejáveis e redução no rendimento de fabricação (Chen et al., 2003; Bersot et al., 2010). Isso ocorre devido às proteases e lipases produzidas pelas psicrotróficas que são termorresistentes e podem possuir atividade residual após a pasteurização e, dessa forma, causar alterações no leite e derivados (Chen et al., 2003).

De acordo com a análise fatorial realizada relacionando-se os grupos de CCS e a composição físico-química do queijo (Tab. 5), a CCS da matéria-prima não afetou a composição do queijo colonial em relação à proteína, gordura, umidade e composição mineral, contradizendo o encontrado na literatura para outros queijos. Coelho et al. (2014) avaliaram o efeito da CCS sobre o queijo muçarela e concluíram que, quando fabricado utilizando-se leite com CCS > 750 mil células $/ \mathrm{mL}$, o teor de proteína no queijo diminuía. Mazal et al. (2007) observaram que, em leite com alta CCS, pode ocorrer a inibição da cultura láctica adicionada pelos fatores inibidores produzidos pelos leucócitos presentes, o que impede a alteração do $\mathrm{pH}$ da massa de queijo (processo necessário para a adequada sinérese da massa), resultando em queijo prato com $2 \%$ a mais de umidade comparado aos queijos produzidos com leite de baixa CCS. A alta umidade nos queijos aumenta a atividade de água para os microrganismos e pode, portanto, reduzir a vida de prateleira desses produtos, devido à deterioração precoce.

Além disso, o queijo colonial ainda não possui um regulamento técnico de identidade e qualidade (RTIQ). O Mapa o enquadra como queijo semigorduroso (25,0 a $44,9 \%$ de gordura) e de média umidade (36 a 45,9\%), conforme a Portaria $\mathrm{n}^{\circ} 146$ (Brasil, 1996). As médias encontradas para as características físicoquímicas, de acordo com o nível de CCS (Tab. 4), reúnem informações que poderão ser úteis para a caracterização futura desse tipo de queijo e, assim, iniciar a produção de queijos padronizados.

\section{CONCLUSÃO}

A elevada contagem de células somáticas influencia negativamente o rendimento simples e seco do queijo colonial em escala industrial, com maiores perdas de componentes sólidos no soro de queijo, diminuindo, dessa forma, a eficiência de fabricação dos queijos. A elevada contagem de células somáticas não afeta a composição físico-química dos queijos coloniais produzidos em escala industrial. Ressalta-se a necessidade da criação de um RTIQ para queijos coloniais, para que sejam fixados valores de referência para composição desse tipo de queijo.

\section{AGRADECIMENTOS}

Ao Conselho Nacional de Desenvolvimento Científico e Tecnológico (CNPq), pelo financiamento do projeto; à Coordenação de Aperfeiçoamento de Pessoal de Nível Superior (Capes), pela bolsa de estudo concedida; à indústria parceira, por permitir a elaboração do experimento; e à Embrapa Suínos e Aves, pelas análises físico-químicas dos queijos.

\section{REFERÊNCIAS}

AKERS, R.M.; NICKERSON, S.C. Mastitis and its impact on structure and function in the ruminant mammary gland. J. Mamm. Gland Biol. Neoplasia, v.16, p.275-289, 2011.

ALESSIO, D.R.M.; THALER NETO, A.; VELHO, J.P. et al. Multivariate analysis of lactose content in milk of Holstein and Jersey cows. Semin. Ciênc. Agrár., v.37, p.2641, 2016.

AULDIST, M.J.; HUBBLE, I.B. Effects of mastitis on raw milk and dairy products. Aust. J. Dairy Technol., v.53, p.28-37, 1998.

BERSOT, L.S.; PEREIRA, J.G.; BARCELLOS, V.C. et al. Quantificação de microrganismos indicadores de qualidade em leite cru ao longo do transporte. Rev. Inst. Latic. Candido Tostes, v.65, p.9-13, 2010.

BOLAND, F.; O'GRADY, L.; MORE, S.J. Investigating a dilution effect between somatic cell count and milk yield and estimating milk production losses in Irish dairy cattle. J. Dairy Sci., v.96, p.1477$1484,2013$.

BRASIL. Ministério da Agricultura Pecuária e Abastecimento. Inspeção Industrial e Sanitária de Produtos de Origem Animal, de 29 de março de 1952 que dispõe sobre o regulamento da inspeção industrial sanitária de produtos de origem animal. Diário Oficial da União. Brasília, 29 de março de 1952. p.13.

BRASIL. Ministério da Agricultura Pecuária e Abastecimento. Instrução Normativa ${ }^{\circ} 62$. Oficializar os métodos analíticos oficiais para análises microbiológicas para controle de produtos de origem animal e água. Diário Oficial da União, 2003. 
BRASIL. Ministério da Agricultura Pecuária e Abastecimento. Portaria $\mathrm{n}^{\circ} 146$ de 7 de março de 1996. Regulamento técnico de identidade e qualidade de queijos. Diário Oficial da União, Brasília 7 de março de 1996. p.1-5.

BRASIL. Ministério da Agricultura, Pecuária e Abastecimento. Instrução Normativa $\mathrm{n}^{\circ}$ 62, de 29 de dezembro 2011, aprova o regulamento técnico de produção, identidade e qualidade do leite tipo A. Diário Oficial da União. Brasília, de 29 de dezembro de 2011

BRASIL. Ministério da Agricultura, Pecuária e Abastecimento. Instrução Normativa $\mathrm{n}^{\circ} 7$, de 3 de maio de 2016. O Regulamento técnico de identidade e qualidade de leite cru refrigerado, o regulamento técnico da coleta de leite cru refrigerado e seu transporte a granel. Diário Oficial da União. Brasília, de 3 de maio de 2016.

CHEN, L.; DANIEL, R.M.; COOLBEAR, T. Detection and impact of protease and lipase activities in milk and milk powders. International Dairy J., v.13, p.255-275, 2003

CHEN, S.X.; WANG, J.Z.; VAN KESSEL, J.S.; REN, F.Z.; ZENG, S.S. Effect of somatic cell count in goat milk on yield, sensory quality, and fatty acid profile of semisoft cheese. J. Dairy Sci., v.93, p.1345-54, 2010.

COELHO, K.O.; MESQUITA, A.J.; MACHADO, P.F. et al. Efeito da contagem de células somáticas sobre o rendimento e a composição físico-química do queijo muçarela. Arq. Bras. Med. Vet. Zootec., v.66, p.1260-1268, 2014.

COMPENDIUM of methods for the microbiological examination of foods, 4.ed. Washington: APHA, 2001.

FURTADO, M.M. Principais problemas dos queijos: causas e prevenções. São Paulo: Fonte Comunicações, 2005. 256p

KLEI, L.; YUN, J.; SAPRU, A. et al. Effects of milk somatic cell count on cottage cheese yield and quality. J. Dairy Sci., v.81, p.1205-1213, 1998.

LE ROUX, Y.; LAURENT, F.; MOUSSAOUI, F. Polymorphonuclear proteolytic activity and milk composition change. Vet. Res., v.34, p.629-645, 2003.

MA, Y.; RYAN, C.; BARBANO, D. M. et al. Effects of somatic cell count on quality and shelf-life of pasteurized fluid milk. J. Dairy Sci., v.83, p.264-274, 2000 .
MATIOLI, G.P.; PINTO, S.M.; ABREU, L.R.D.; XAVIER, L.; TEIXEIRA, L.A.M. Influência do leite proveniente de vacasmastísticas no rendimentode queijo Minas frescal. nome do artigo. www.arvoredoleite.org. Rev. Inst. Latic. Candido Tostes, v.34, p.38-54, 2000.

MAZAL, G.; VIANNA, P.CB.; SANTOS, M.V.; GIGANTE, M.L. Effect of somatic cell count on prato cheese composition. J. Dairy Sci., v.90, p.630-636, 2007.

MÉTODOS físico-químicos para análise de alimentos. São Paulo, 2008. [1020p.].

MURPHY, S.C.; BOOR, K.J. Trouble-shooting sources and causes of high bacteria counts in raw milk. Dairy Food Environ. Sanit., v.20, p.606-611, 2000

PINTO, C.L.O.; MARTINS, M.L.; VANETTI, M.C.D. Qualidade microbiológica de leite cru refrigerado e isolamento de bactérias psicrotróficas proteolíticas. Ciênc. Tecnol. Alimen., v.26, p.645651, 2006.

POLITIS, I.; NG-KWAI-HANG, K.F. Association between somatic Cell count of milk and cheeseyielding capacity. J. Dairy Sci., v.71, p.1720-1727, 1988.

SCHALLIBAUM, M. Impact of SCC on the quality of fluid milk and cheese. In: NATIONAL MASTITIS COUNCIL ANNUAL MEETING, 40., 2001. Liebefeld. Proceedings... Liebefeld: NMC, 2001 p.38-46.

SILVA, M.A.P.; SANTOS, P.A.; LEÃO, K.M. et al. Qualidade do leite na indústria de laticínios. Rev. Inst. Latic. Candido Tostes, v.69, p.23-28, 2010.

VIANNA, P.C.B.; MAZAL, G.; SANTOS, M.V.; BOLINI, H.M.A; GIGANTE, M.L. Microbial and sensory changes throughout the ripening of Prato cheese made from milk with different levels of somatic cells. J. Dairy Sci., v.91, p.1743-1750, 2008. Available in: <http://www.ncbi.nlm.nih.gov/pubmed/18420604>. Accessed in: 25 Apr. 2014. 